MATEC Web of Conferences 10, 06003 (2014)

DOI: $10.1051 /$ matecconf/ 20141006003

(C) Owned by the authors, published by EDP Sciences, 2014

\title{
Evaluation of Fire Hazard and Safety Management of Heritage Buildings in Georgetown, Penang
}

\author{
M.A. Othuman Mydin ${ }^{1, a}$, N. Md Sani ${ }^{2}$, N.F. $\operatorname{Abas}^{3}$, Y.Y. Khaw ${ }^{4}$ \\ ${ }^{1,2,3,4}$ School of Housing, Building and Planning, Universiti Sains Malaysia, 11800 Penang, Malaysia
}

\begin{abstract}
Fire is a subject that is always neglected and ignored as far as heritage buildings are concerned. Unlike newly-built buildings, which are required under UBBL to undergo certain fire protection system tests, people are less likely to carry out such tests and detailed assessments for heritage buildings. Thus, this research is significant as it is aimed at accomplishing several objectives including studying the current fire emergency plan, besides identifying and assessing the possible fire hazards in heritage buildings in Penang. Several case studies were carried out at a few premises such as the Khoo Kongsi, Cheah Kongsi, Hock Teik Chen Shin Temple and the Teochew Temple with the aid of the Fire Rescue Department Malaysia (FRDM). The results obtained from this study will be discussed according to several aspects focusing on general health and safety management at the site, the fire-fighting system, fire exit routes and signage at the temples, fire hazards, and fire detection and alarm.
\end{abstract}

\section{Introduction}

It is broadly acknowledged that fire is one of the greatest threats, not only to the occupants of a building, but also to its fabric and contents. It can cause the total destruction of a building and its contents within a few hours, and its primary impact is the potential loss of authenticity - which is, after all, the quality from which the importance of our cultural heritage flows [1,]. Fire has long been an adversary of heritage buildings and their structures, with some older structures falling victim several times $[2,3]$. It has also been pointed out that several heritage buildings were badly damaged or burnt down by fire in Malaysia, including the People's Museum, Melaka in 2001, Rumah Pak Ali, Gombak in 2003 and the Sarawak Club, Kuching in 2006.

There are a few factors that contributed to the fires in these unique yet vulnerable heritage buildings [4]. Most of the heritage buildings are large scale buildings with flammable priceless contents, large numbers of visitors, and existing structures which are weak with regard to fire resistance [5]. Fire risk assessment is an assessment of the risks to people and property as a result of unwanted fires [6].

Thus, it plays an important role as many historic buildings in Penang are of significant architectural value and historical importance, and their destruction by fire would be an irreplaceable loss [7]. The basic elements of management planning for fires in heritage buildings and collections are to understand the risks of fire, to alleviate those risks and to prepare for a potential fire while considering the conservation requirements of the building and / or the collection [8].

\footnotetext{
${ }^{a}$ Corresponding author: azree@usm.my
} 


\section{Site Selections}

The proposed buildings for carrying out this study included the Khoo Kongsi, Cheah Kongsi, Hock Teik Chen Shin Temple and Teochew Temple. It was carried out to investigate previous fire cases that took place in heritage buildings with the aid of the Fire Rescue Department Malaysia. The residents of the building were then interviewed and site observations were also conducted. Data was obtained from the interviews that were carried out during the case study with the persons in charge of the buildings. Besides that, the Station Head of the Fire Rescue Department Malaysia, Beach Street in Penang was interviewed in order to obtain more information about the current situation in the whole Georgetown Heritage Site. Other sources for obtaining data under this research included journals, books, articles, UBBL and data provided by the FRDM.

\section{Data Collection and Discussions}

\subsection{Khoo Kongsi}

The fire hazards in the Khoo Kongsi come mainly from joss sticks. Joss sticks are used for ancestral worship. Almost $70 \%$ of the worship hall is made up of timber (Figure 1). Timber is a highly flammable building material. It can be one of the main fire hazards in the temple. There is no procedure currently to prevent the accumulation of combustible materials in the Khoo Kongsi.

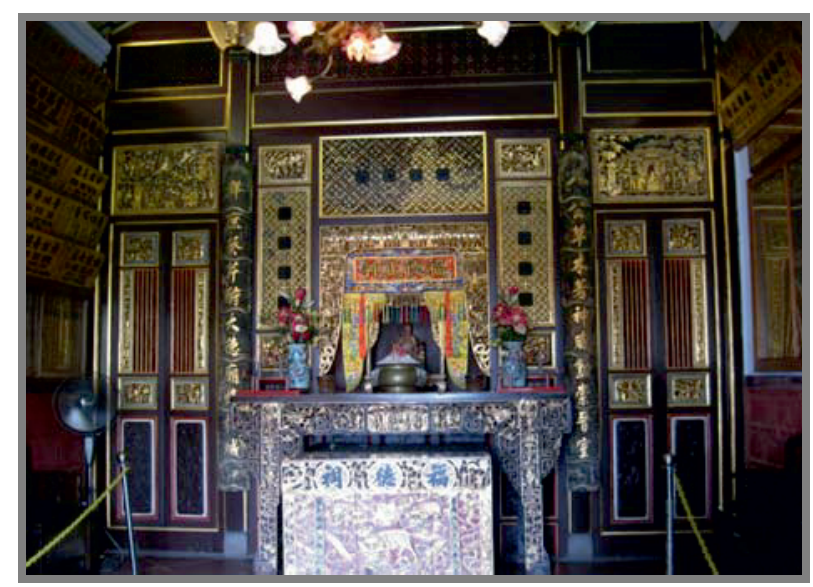

Figure 1. Typical worship hall, more than $70 \%$ of which is made up of timber

The flammable materials and substances are kept properly in a store behind the worship hall. It is more organized compared to other clan houses. There are no flammable gases, explosive materials or flammable solvents in the Khoo Kongsi. There are some portable appliances and switches, which are well-guarded and securely fixed in position at a safe distance away from all combustible materials.

Generally, in terms of health and safety management, the administration has not documented the health and safety policy for Khoo Kongsi. There is no competent person in charge to specifically handle health and safety issues in the Khoo Kongsi. Under the requirements of the Management of Health and Safety at Work Regulations, there should be a person in charge of health and safety issues.

In terms of fire-fighting, the Khoo Kongsi definitely has a sufficient number of fire-fighting appliances / equipment located throughout the ancestral temple. Fire extinguishers are easily found everywhere. These fire extinguishers are located near to the sites of higher fire risk such as the worship hall, which is full of timber-made items. The portable extinguishers used are of the Type A, ABC Powder fire extinguisher, which is the correct type for the identified fire risk. According to Miss 
Yeap, the fire-fighting appliances are certified by FRDM personnel annually. All the fire extinguishers in the Khoo Kongsi are properly colour-coded.

\subsection{Cheah Kongsi}

The fire hazards in the Cheah Kongsi also come from joss sticks which are used for ancestral worship. It is obvious that the building is mainly constructed from timber, which is highly flammable (Figure 2). This could be another important fire hazard element that one should be aware of. The building is not a non-smoking building, so there might be some smoking hazards from cigarettes too. The main electrical installations are inspected and are in good condition. There is no procedure currently to prevent the accumulation of combustible materials in the Cheah Kongsi.

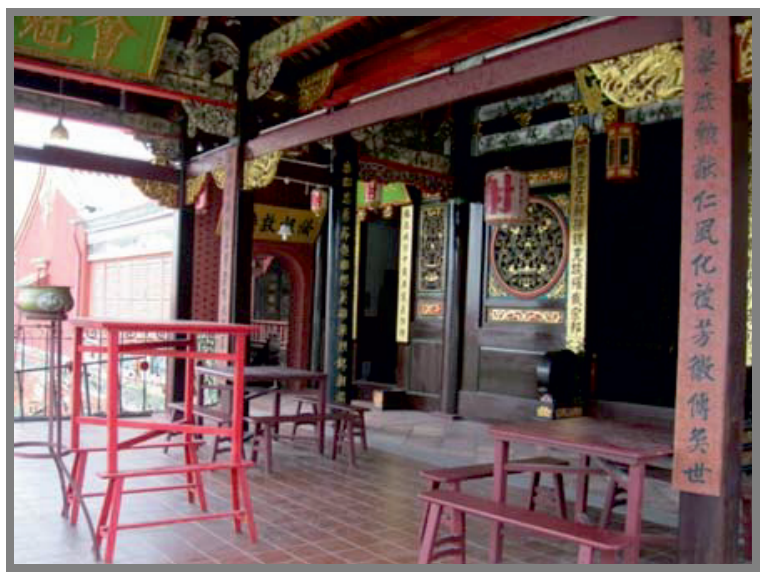

Figure 2. Timber-made ancestral hall of the Cheah Kongsi

Generally, in terms of health and safety management, the administration has not documented the health and safety policy of the Cheah Kongsi. There is no competent person in charge to specifically handle health and safety issues in the Cheah Kongsi. Actually, they are not even aware that under the requirements of the Management of Health and Safety at Work Regulations there should be a person in charge of these health and safety issues. General health and safety management elements still need to be reviewed in the Cheah Kongsi.

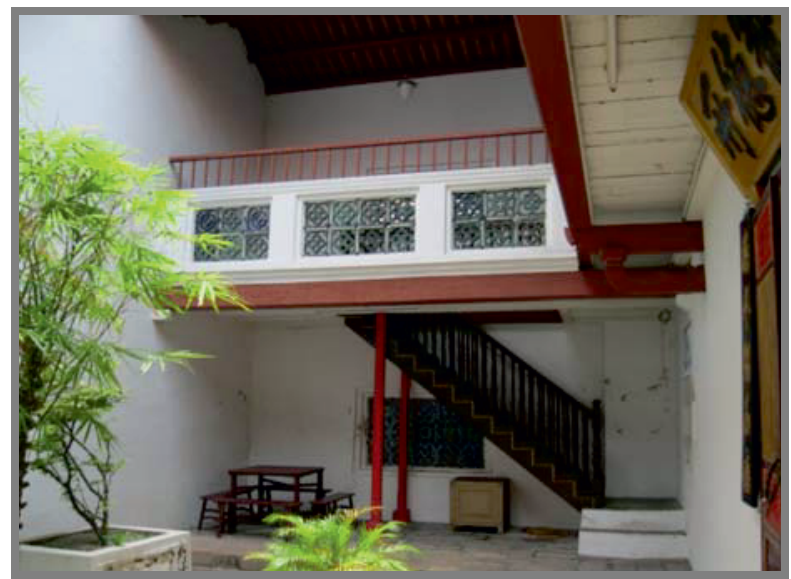

Figure 3. Staircase free from obstruction

In terms of fire-fighting, the Cheah Kongsi has a certain number of fire-fighting appliances located throughout the ancestral temple. There are around 10 fire extinguishers across the 16,146 sq. $\mathrm{ft}$. ancestral temple. These fire extinguishers are located near to the sites of higher fire risk, such as the 
worship hall, which is full of timber-made items. The portable extinguishers used are of the Type A, $\mathrm{ABC}$ Powder fire extinguisher, which is the correct type for the identified fire risk. The fire-fighting appliances are certified by FRDM personnel annually. All the fire extinguishers are properly colourcoded.

All the registered fire extinguishers in the Cheah Kongsi are well-maintained. All the fire exit routes and the points of exit from the building are clear of obstruction, as shown in Figure 3. All the floor surfaces and stairs along the escape routes in the Cheah Kongsi are free from tripping and slipping hazards as well. No lighting is provided along the escape routes in cases of emergency. Furthermore, there is no escape route plan showing different directions to guide visitors to places of safety in the Cheah Kongsi.

\subsection{Penang Teochew Association}

The fire hazards in the Penang Teochew Association come mainly from joss sticks. Joss sticks are used for ancestral worship. The building is made up of less timber compared to other ancestral temples. However, the worship hall is still made up of a large amount of timber, as shown in Figures 4 and Figure 5. This highly flammable building material can be one of the main fire hazards of the temple. The building is not a non-smoking building, so there might be some smoking hazards from cigarettes too.

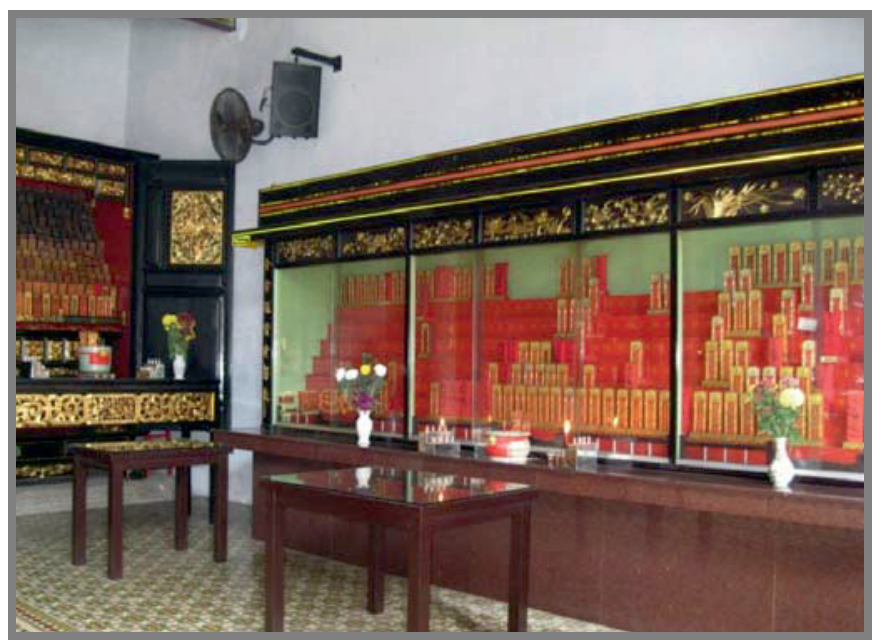

Figure 4. The worship hall of the Teochew Association, Penang

The flammable materials and substances are kept properly in a store behind the worship hall, as shown in Figure 6. It is well-organised. There are no flammable gases, explosive materials or flammable liquids / solvents in the Penang Teochew Association. There are some portable appliances and switches, which are well-guarded and securely fixed in position at a safe distance. These have been fixed away from all combustible materials. As there is a family of 6 living in the Penang Teochew Association, there will be some hot surfaces or portable heat hazards, which mainly originate from the kitchen. 


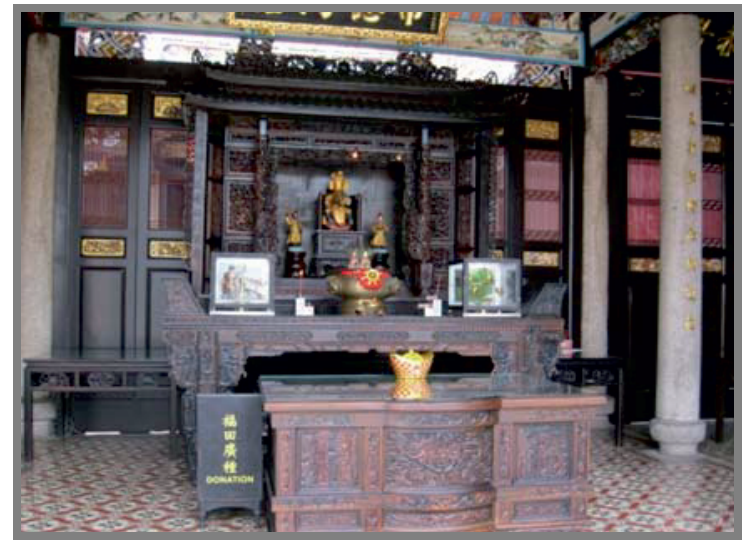

Figure 5. The worship hall of the Teochew Association, Penang

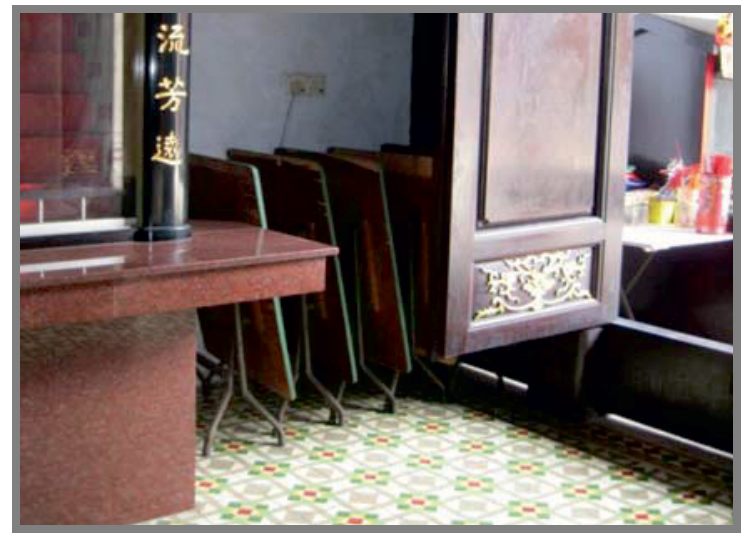

Figure 6. The flammable materials and substances are kept properly in a store behind the worship hall

In general, in terms of health and safety management, the administration has not documented the health and safety policy of the Penang Teochew Association. There is no competent person in charge to specifically handle health and safety issues in the Penang Teochew Association. Under the requirements of the Management of Health and Safety at Work Regulations, there should be a person in charge of health and safety issues.

In terms of fire-fighting, the Penang Teochew Association has around 10 portable fire extinguishers placed around the ancestral temple. The fire extinguishers can be easily found. These fire extinguishers are located near to the sites of higher fire risk such as the worship hall, which is full of timber-made items. The portable extinguishers used are of the Type A, ABC Powder fire extinguisher, which is the correct type for the identified fire risk.

\subsection{Hock Teik Cheng Sin Temple}

The fire hazards in the Hock Teik Cheng Sin Temple come mainly from joss sticks. Joss sticks are used for ancestral worship. The building is beautifully decorated with flammable timber-made crafts, as shown in Figure 7. The building is not a non-smoking building, so there might be some smoking hazards from cigarettes too. The main electrical installations are properly inspected and checked. However, there is no testing procedure in place for the portable electrical appliances. It would be good to carry out the electrical testing in order to help prevent electrical fires. There is no procedure currently to prevent the accumulation of combustible materials in the Hock Teik Cheng Sin Temple. 


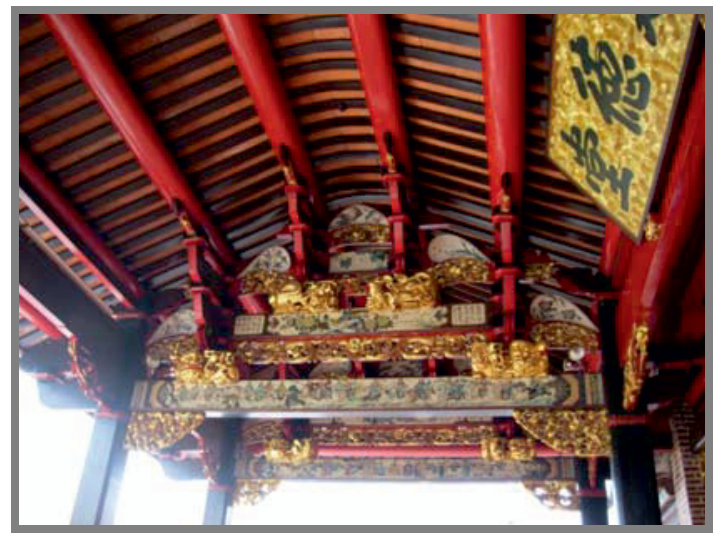

Figure 7. Timber-made crafts in the Hock Teik Cheng Sin Temple

The flammable materials and substances are not well-kept, as shown in Figure 8. It is less organized as compared to other clan houses. The materials for worship are placed along the corridor. However, there are no flammable gases, explosive materials or flammable solvents in the Hock Teik Cheng Sin Temple. There are some well-guarded portable appliances and switches, which are securely fixed away from all combustible materials. There are no hot surfaces or portable heat-hazards in the Hock Teik Cheng Sin Temple. The clan house is not occupied by anyone, thus there are no fire hazards from the kitchen.

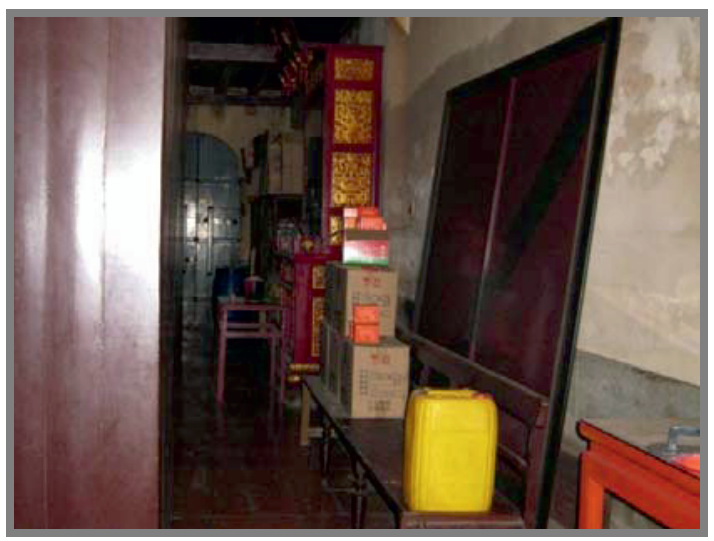

Figure 8. The flammable materials and substances are not well-kept

Generally, in terms of health and safety management, the administration has not documented the health and safety policy of the Hock Teik Cheng Sin Temple. Also, there is no competent person in charge to specifically handle health and safety issues in the Hock Teik Cheng Sin Temple. Under the requirements of the Management of Health and Safety at Work Regulations, there should be a person in charge of health and safety issues. Besides, there is no documentation regarding the risk assessment for all the general works that are carried out.

In terms of fire-fighting, the Hock Teik Cheng Sin Temple has no fire-fighting appliances throughout the ancestral temple. This is due to the lack of awareness among the trustees. Fire extinguishers should be placed near to the sites of higher fire risk such as the worship hall, which is filled with timber-made items. They should install fire-fighting appliances and make sure the appliances are certified / checked by FRDM personnel annually. The staff and guards working in the Hock Teik Cheng Sin Temple should be aware of the usage of fire extinguishers according to the different classifications of fire too. In the Hock Teik Cheng Sin Temple, there is no policy on firefighting. 


\section{Conclusions}

It is clear that the ancestral temples in Georgetown, Penang have not achieved a high level of fire risk protection awareness. Although the fire risks are moderate, obviously a lot more can be done to prevent the outbreak of fire in these beautiful buildings. In order to treasure the heritage value of the buildings, efforts made to protect them should be parallel to our love for these buildings. The fire protection systems in these buildings are still very limited. The fire protection system is of a very simple and basic level, where only fire extinguishers are provided. In order to increase the fire protection in these ancestral temples, it is advisable that the owners seek advice from the FRDM. In conclusion, a lot can still be done to enhance the fire protection systems in the ancestral temples in Georgetown, Penang. All the heritage elements in these buildings are so valuable that no one can afford to lose them in any possible fire outbreak. A little more effort done today will surely make things a lot different in the future.

\section{References}

1. M. Nasiri, Skidding Routes Simulation for Opening Access to High-Risk Fire Areas, World Applied Sciences Journal, 16 (2) (2012) 791-798

2. H.N. Salleh, A.G. Ahmad, Fire Safety Management In Heritage Buildings: The Current Scenario In Malaysia, 22nd CIPA Symposium, 2009, pp. 4-6.

3. M.N. Ibrahim, K. Abdul-Hamid, M.S. Ibrahim, A. Mohd-Din, R.M. Yunus, M.R. Yahya, The Development of Fire Risk Assessment Method for Heritage Building. 2nd International Building Control Conference, 20 (2011) 317-324

4. G. Ramachandran, Fire Safety Management and Risk Assessment, Facilities, 17 (9/10) (1999) 363-367

5. S. Rahman, Heritage Management Challenges in Historic Town of Ludlow, England, World Applied Sciences Journal, 24 (12) (2013) 1589-1596

6. N.H. Salleh, Fire Safety Management in Heritage Buildings: The Current Scenario in Malaysia, 2009.

7. W.K. Chow, Proposed Fire Safety Ranking System EB-FSRS for Existing High-Rise NonResidential Buildings in Hong Kong, ASCE Journal of Architectural Engineering, 8 (4) (2002) 116-124

8. J.M. Watts Jr, M.E. Kaplan, Fire Risk Index for Historic Buildings, Fire Technology, 37 (2011) 167-180 